\title{
Influência da Concentração e Purificação da Argila na Estrutura e Permeação ao Vapor de Água de Nanocompósitos PEBDL/Bentonita
}

\author{
Eduardo M. Silva, M Goretti F. Coutinho, Raquel B. Costa, Laura H. de Carvalho \\ Unidade Acadêmica de Engenharia de Materiais, Universidade Federal de Campina Grande, Campina Grande PB (Brasil) \\ Eduardo L. Canedo \\ PolyTech, Prospect CT (USA)
}

\begin{abstract}
Resumo: Este trabalho tem por objetivo a preparação, caracterização e avaliação da permeabilidade ao vapor de água de filmes nanocompósitos poliméricos. Um polietileno linear de baixa densidade linear (PEBDL) foi utilizado como matriz e uma argila bentonita Paraibana na sua forma natural, purificada e organofilizada foi adicionada à matriz em concentrações de 1 a $2 \%$ em massa. As argilas e os nanocompósitos foram caracterizados por espectroscopia no infravermelho (FTIR) e por difração de raios x (DRX). A permeação ao vapor de água dos filmes foi determinada em função do teor e modificação da carga mineral. Os resultados mostram que a purificação (remoção de matéria orgânica) e que a organofilização da carga foram eficientes e que nanocompósitos com morfologia intercalada foram obtidos em todos os casos. A presença de carga aumentou significativamente a permeabilidade dos filmes ao vapor de água, mas os efeitos da purificação e/ou organofilização da argila, bem como do teor de carga, nesta propriedade, foram discretos.
\end{abstract}

Palavras-chave: PEBDL, bentonita, nanocompósitos, filmes, permeabilidade.

\section{Effect of Loading Level and Clay Purification on the Structure and Water Vapor Permeability of LLDPE/ Bentonite Nanocomposites}

\begin{abstract}
This work is concerned with the preparation, characterization and measurement of water vapor permeability of LLDPE/ bentonite nanocomposite films, containing $1 \%$ and $2 \%$ of natural, purified, and organophilized clay. FTIR and XRD techniques were used to characterize the clay and the composites. The results pointed to an effective clay purification procedure (removal of organic matter). Mostly intercalated nanocomposites were obtained in all cases. The addition of clay significantly increased the permeability of the films to water vapor. However, purification and/or organophilization of the clay, as well as loading level, were found to have little effect on the permeability.
\end{abstract}

Keywords: LLDPE, bentonite, nanocomposites, films, permeability.

\section{Introdução}

A preparação e adequação do desempenho materiais a aplicações específicas é um dos principais objetivos da engenharia de materiais. Uma forma de se atingir estes objetivos é através da incorporação e dispersão de cargas inorgânicas, particuladas ou fibrosas, em matrizes poliméricas. Dessa forma, obtêm-se materiais compósitos (sistemas híbridos) com propriedades superiores e distintas dos seus componentes individuais. Recentemente, observou-se que a utilização de cargas minerais dispersas em escala nanométrica na matriz polimérica resultam em produtos com propriedades semelhantes às de compósitos convencionais, porém em níveis de carregamento muito inferiores. Em outras palavras, nanocompósitos com teores de carga de 1 a $5 \%$ podem apresentar propriedades equivalentes a de compósitos convencionais ou microcompósitos com 20 a $40 \%$ de carga em escala micrométrica. $\mathrm{O}$ uso de baixos níveis de carga de tamanho muito diminuto resulta tanto em ganhos no processamento (menor viscosidade, menor desgaste dos equipamentos, menor consumo de energia) quanto em produtos mais leves (importante para a indústria de transportes) e mais transparentes ou translúcidos (importante para embalagens de alimentos $)^{[1]}$.

Os silicatos em camadas estão entre as cargas mais utilizadas para a preparação de nanocompósitos poliméricos e a argila bentonita, formada por silicatos em camadas, vem sendo muito empregada para este fim. O estado de Paraíba apresenta-se como o principal produtor de bentonitas no Brasil. Atualmente, nove empresas de mineração atuam no estado, concentradas no município de Boa Vista; dentre elas, a principal empresa produtora de bentonita no país, a Bentonit União Nordeste (BUN).

Bentonitas são argilas constituídas pelo argilomineral montmorilonita (seu principal - $80 \%$ - componente) e impurezas minerais (quartzo, caulinita, etc.) e orgânicas (ácidos húmicos) que representam cerca de $20 \%$ de sua massa. A montmorilonita é um mineral do grupo das esmectitas, ou seja, um aluminosilicato hidratado com estrutura cristalina formada por camadas compostas de uma de folha octaédrica (alumina) entre duas folhas tetraédricas (sílica), unidas entre si por oxigênios comuns. As camadas triplas estão unidas por ligações fracas, o que permite sua separação com relativa facilidade em condições apropriadas ${ }^{[2]}$.

Substituições isomórficas do $\mathrm{Si}^{+4}$ por $\mathrm{Al}^{+3}$ na folha tetraédrica e de $\mathrm{Al}^{+3}$ por $\mathrm{Mg}^{+2}$ na folha octaédrica resultam em uma carga negativa líquida nas camadas cristalinas, que é compensada pela incorporação de cátions inorgânicos hidratados $\left(\mathrm{Na}^{+}\right.$e $\mathrm{Ca}^{+2}$ predominante nas bentonitas sódicas ou cálcicas, respectivamente) no espaço entre camadas (ou espaço interlamelar) da montmorilonita. Os cátions do espaço interlamelar podem ser facilmente trocados por cátions orgânicos. Sais de amônio ou fosfônio quaternários, com volumosos grupos apolares são comumente utilizados na troca catiônica durante o processo de organofilização do argilomineral. 
Dessa forma, aumenta a distância entre as camadas cristalinas e o espaço interlamelar se torna menos hidrofílico e mais afim com cadeias poliméricas apolares, que podem se intercalar entre as camadas quando a organomontmorilonita é dispersa em uma matriz polimérica apropriada. Eventualmente, as camadas podem ser separadas, seja individualmente ou pequenas pilhas ou tactoides, resultando na esfoliação do mineral, disperso na matriz polimérica em escala nanométrica ${ }^{[2-5]}$.

Vale salientar que a carga geralmente adicionada à matriz polimérica consiste em argila bentonita e não no argilomineral montmorilonita. A presença de impurezas orgânicas e inorgânicas na argila, além do silicato em camadas (montmorilonita), afeta tanto o processo de organofilização quanto a dispersão da carga na matriz polimérica. Por isso, é conveniente investigar o efeito da purificação da argila antes de sua utilização ${ }^{[3]}$.

Por utilizar equipamentos e procedimentos usuais no processamento de termoplásticos, resultando em baixos custos de preparação, o método mais comum para a obtenção de nanocompósitos de matriz poliolefinica é a intercalação no estado fundido ${ }^{[6]}$. Poliolefinas encontram várias aplicações no mercado de embalagens, inclusive na área de filmes poliméricos para aplicações alimentícias ou não.

O uso de nanocompósitos poliméricos para a produção de filmes para acondicionamento de alimentos é interessante já que a incorporação da carga nanoparticulada à matriz polimérica tem a capacidade de afetar a permeação de gases e vapores através do filme. Essa propriedade depende da concentração, origem, razão de aspecto e orientação da nanocarga inserida na matriz polimérica ${ }^{[7,8]}$. Entre os polímeros empregados como matriz na preparação de filmes para a indústria de embalagens de alimentos destaca-se o polietileno de baixa densidade linear (PEBDL). O PEBDL é um polímero flexível, inerte, com baixa permeabilidade ao vapor de água e boas propriedades de termosoldagem ${ }^{[9]}$.

A permeação através de um filme polimérico ocorre através de três estágios: a sorção das moléculas do gás na superfície do filme, a difusão do gás através do filme de acordo com a lei de Fick e, por fim, a dessorção do gás na superfície oposta do filme. Em princípio, espera-se a redução na difusividade do gás em nanocompósitos se comparados com a difusividade na matriz de polímero puro, uma vez que os tactoides de argila forçam caminhos mais tortuosos para a permeação das moléculas do gás ${ }^{[10]}$. No entanto, o oposto pode ocorrer caso a presença das cargas gere porosidade ou defeitos superficiais que gerem caminhos livres para a difusão do gás através do filme ${ }^{[11]}$.

O objetivo deste trabalho é a preparação e caracterização de compósitos de matriz de PELBD contendo $1 \%$ e $2 \%$ de argila bentonita natural, purificada, organofilizada, e purificada/ organofilizada. As argilas foram caracterizadas por espectroscopia no infravermelho (FTIR) e difração de raios x (DRX); e os compósitos por DRX. A permeabilidade ao vapor de água de filmes planos da matriz pura e dos compósitos foi determinada.

\section{Experimental}

\section{Material}

A matriz é um polietileno linear de baixa densidade, código LL218, fornecido em grânulos. O polietileno copolimerizado com $n$-buteno, produzido pelo processo Spherilene e aditivado com antioxidante. Índice de fluidez 2,3 dg/min, (ASTM D1238, condição $2,16 \mathrm{~kg} / 190{ }^{\circ} \mathrm{C}$ ); resina fabricada e doada pela Braskem, São Paulo, SP, Brasil.

A carga é uma bentonita sódica, código BRASGEL, fornecida pela Bentonit União Nordeste (BUN), Campina Grande, PB, Brasil, sob a forma de pó com tamanho médio de partículas $\leq 74 \mu \mathrm{m}$. O agente organofilizante é o brometo de hexadecil trimetil amônio, de nome comercial Cetremide, fornecido pela Vetec, Recife, PE, Brasil.

\section{Métodos}

\section{Purificação da argila}

A matéria orgânica foi removida utilizando o procedimento descrito por Araújo et al. ${ }^{[12]}$. Uma dispersão aquosa a $2 \%$ da bentonita sódica foi misturada a uma solução tampão $(\mathrm{pH}=5)$ e homogeneizada por agitação. Uma solução de peróxido de hidrogênio a $30 \%$ foi adicionada ao sistema mantido sob agitação por 1 minuto com o auxilio de um agitador magnético. Terminada a homogeneização, o sistema foi deixado em repouso por 24 horas na temperatura ambiente. Decorrido esse período, a dispersão foi aquecida a $50{ }^{\circ} \mathrm{C}$ segundo procedimentos de Camargo et al. ${ }^{[13]} \mathrm{e}$ mantida nesta temperatura por 72 horas. Terminada a reação, as amostras foram recuperadas por centrifugação, lavadas com água destilada, filtradas, peneiradas em peneira ABNT \#270; o material passante foi seco em estufa a $60{ }^{\circ} \mathrm{C}$. O material purificado e seco foi pulverizado em almofariz e peneirado em peneira ABNT \#200 (0,074 mm).

\section{Organofilização da argila}

A capacidade de troca de catiônica (CTC) da argila foi determinada pelo método do azul de metileno ${ }^{[14]}$, resultando no valor de $0,84 \mathrm{mEq} \cdot \mathrm{g}^{-1}$. Uma dispersão aquosa a $1 \% \mathrm{em}$ peso de argila em água destilada foi mantida sob agitação e aquecida $80^{\circ} \mathrm{C}$. Em seguida o sal orgânico na proporção de $110 \%$ da CTC da argila, foi adicionado à dispersão e o sistema agitado vigorosamente ( $3000 \mathrm{rpm}$ ) durante 30 minutos. Completado o tempo total de agitação, o aquecimento foi interrompido, o recipiente fechado e o sistema deixado em repouso por 24 horas na temperatura ambiente. Passado este tempo, centrifugou-se a dispersão, lavou-se com água destilada para remover o excesso de sal, filtrou-se e secou-se em estufa a $60{ }^{\circ} \mathrm{C}$ por um período de 48 horas. As argilas modificadas foram desagregadas com almofariz e passadas em peneira ABNT \# 200 (0,074 mm); a fração passante foi utilizada.

\section{Obtenção dos nanocompósitos na forma de filmes}

Para o processamento dos filmes, concentrados com $30 \%$ de argila e $70 \%$ de matriz de polietileno foram preparados em um misturador interno Haake Rheomix 600 , que operou a $140{ }^{\circ} \mathrm{C}$ com rotores do tipo "roller" a velocidade de $60 \mathrm{rpm}$ durante 5 minutos. Em seguida os concentrados foram granulados em um moinho de facas e misturados com a matriz de polietileno de modo a se obter concentrações de $1 \%$ e $2 \%$ em massa da argila. As misturas foram extrusadas a $27 \mathrm{rpm}$ com um perfil de temperatura de 200/190/180 ${ }^{\circ} \mathrm{C}$ na extrusora monorosca de bancada AX-Plásticos (16-mm), específica para produção de filmes planos. Filmes de espessura entre 20 e $50 \mu \mathrm{m}$ foram produzidos.

\section{Espectroscopia de absorção no Infravermelho (FTIR)}

As argilas foram caracterizadas por espectroscopia na região do infravermelho (FTIR) em equipamento PerkinElmer Spectrum $400 \mathrm{em}$ varreduras de $4000-650 \mathrm{~cm}^{-1}$. As amostras de argila foram caracterizadas na forma de pastilhas feitas com $0,007 \mathrm{~g}$ de argila e $0,1 \mathrm{~g}$ de brometo de potássio, prensadas a $5 \mathrm{t}$ durante 30 segundos.

\section{Difração de raios-X (DRX)}

Para analisar e comparar o deslocamento interplanar basal $d_{(001)}$ na argila, e para avaliar a estrutura morfológica dos nanocompósitos, foi utilizado o difratômetro Shimadzu XDR-6000, operando a temperatura ambiente, utilizando a radiação $\mathrm{Cu}_{\mathrm{K}} \alpha$ (comprimento de 
onda $\lambda=0,1542 \mathrm{~nm}$ ) e varredura angular $2 \theta$ de 2 a $12^{\circ}$ a $1^{\circ} / \mathrm{min}$ Para calcular a distância interplanar basal foi utilizada a Lei de Bragg:

$$
d_{(001)}=\frac{\lambda}{2 \operatorname{sen} \theta}
$$

\section{Microscopia Eletrônica de Varredura}

As superfícies das amostras dos nanocompósitos foram recobertas com ouro e analisadas em um microscópio eletrônico de varredura, da marca Shimadzu modelo SSX-550, operando com voltagem de $15 \mathrm{kV}$.

\section{Ensaio de permeabilidade ao vapor de água}

A permeabilidade dos filmes ao vapor de água foi determinada por gravimetria, método baseado na norma ASTM E92, com correções para a umidade do ar. Foram utilizados para a realização dos testes potes de vidro com o formato cilíndrico com aproximadamente metade de seu volume de água. Em seguida recortaram-se amostras de cada filme e colocaram-se sobre os potes de forma a ficarem hermeticamente fechados e colocados em uma área isolada com o pote do centro contendo ácido sulfúrico para garantir uma atmosfera com umidade relativa de aproximadamente $15 \%$ e à temperatura ambiente $\left(26\right.$ a $\left.27^{\circ} \mathrm{C}\right)$. As pesagens foram realizadas em intervalos de tempos pré-determinados. Avaliou-se a permeação do vapor de água através dos filmes em intervalo de tempo longos (mais de 115 horas), a partir da perda de massa dos potes por unidade de área em condições em que o processo de transferência de massa atinge o estado estacionário.

Nessas condições, o fluxo de vapor de água através do filme $(N)$ é diretamente proporcional à diferença de pressão parcial de água no ar em contato com as duas faces do filme $(\Delta p)$ e inversamente proporcional à espessura do filme $(h)$; a constante de proporcionalidade é um parâmetro material que chamamos permeabilidade $(P)$ :

$$
N=P \frac{\Delta p}{h}
$$

Usualmente, a quantidade de vapor de água é expressa em termos do volume que ocuparia em condições padronizadas de temperatura e de pressão (STP: $0{ }^{\circ} \mathrm{C}, 1 \mathrm{~atm}$ ) caso se comportasse como um gás ideal. Em função do fluxo mássico $(G)$ :

$$
N=G \frac{V_{0}}{M}
$$

onde $V_{0}=22,414 \mathrm{~cm} 3 \cdot \mathrm{mol}^{-1}$ é o volume molar normal (em condições STP) do vapor de água, e $M=18,011 \mathrm{~g} \cdot \mathrm{mol}^{-1}$ é a massa molar da água. O fluxo mássico (massa que passa através do filme por unidade de área e de tempo) foi determinado experimentalmente utilizando o procedimento descrito, como a inclinação da reta obtida representado graficamente a perda de massa dos potes por unidade de área de filme em função do tempo.

A diferença de pressão parcial de água pode ser expressa em termos da pressão de vapor da água à temperatura do experimento $\left(p_{V}\right)$ e a diferença de umidade relativa do ar entre o interior do pote (onde o ar está saturado de vapor de água) e o exterior $(\Delta u)$ :

$$
\Delta p=p_{V} \Delta u
$$

Substituindo as Equações 3 e 4 na Equação 2 e reordenando para obter $P$ :

$$
P=\frac{G h V_{0}}{M p_{V} \Delta u}
$$
filmes.

A Equação 5 foi utilizada para avaliar a permeabilidade dos

A Tabela 1 apresenta a identificação das amostras analisadas.

\section{Resultados e Discussão}

\section{Caracterização das argilas: FTIR e DRX}

A Figura 1 mostra os espectros na faixa do infravermelho para a bentonita natural (AN), purificada (AP), natural organofilizada (ANO) e purificada organofilizada (APO).

Observa-se a redução da intensidade da banda de absorção na região $3725-3425 \mathrm{~cm}^{-1}$ nas argilas purificadas e/ou organofililizadas, em comparação com a amostra de argila natural. A banda é atribuída aos estiramentos simétricos e assimétricos das ligações $\mathrm{O}-\mathrm{H}$, dos grupos orgânicos (derivados do ácido húmico) presentes em forma de impurezas assim como a água adsorvida ${ }^{[12,13]}$. O espectro das argilas organofilizadas (ANO e APO) revela picos de absorção em $2925 \mathrm{~cm}^{-1}$ e $2850 \mathrm{~cm}^{-1}$ correspondentes às vibrações de deformações axiais simétricas e assimétricas das ligações $\mathrm{C}-\mathrm{H}$ nos grupos $\mathrm{CH}_{3} \mathrm{e}$ $\mathrm{CH}_{2}$ do cátion Cetremide ${ }^{[15,16]}$, evidenciando a incorporação do cátion orgânico. A maior intensidade dos picos na amostra previamente purificada pode indicar uma maior incorporação do sal orgânico como conseqüência da purificação.

A Figura 2 mostra os difratogramas de raios $\mathrm{x}$ das argilas natural (AN), purificada (AP), natural organofilizada (ANO) e purificada organofilizada (APO).

Observa-se também que a organofilização resultou no aumento considerável (aproximadamente 70\%) da distância interlamelar, aproximadamente. Estes resultados confirmam que o sal orgânico foi efetivamente incorporado no espaço interlamelar. As diferenças observadas entre o comportamento da argila natural e purificada sugerem que a purificação da argila (remoção da matéria orgânica) afetou o processo de organofilização. A matéria orgânica presente na argila, muitas vezes, age como coloide protetor, dificultando a troca catiônica ${ }^{[3]}$. Os resultados obtidos no DRX são consistentes com a espectroscopia de absorção no infravermelho (Figura 1) e com os resultados obtidos por Barbosa et al. ${ }^{[17,18]}$.

\section{Caracterização dos filmes: DRX}

A Figura 3 apresenta os difratogramas dos nanocompósitos PEDDL/bentonita com nível de carga de $1 \%$ e $2 \%$ de argila natural (AN), purificada (AP), natural organofilizada (ANO) e purificada organofilizada (APO).

Os difratogramas mostram que a distância interplanar basal da argila nos compósitos foi pouco afetada pela purificação e/ou organofilização das bentonitas, ou pelo teor de carga (1\% e $2 \%$ ). Os valores de $d_{001}$ observados, intermédios entre os obtidos para argilas

Tabela 1. Identificação das amostras.

\begin{tabular}{ll}
\hline \multicolumn{1}{c}{ Amostra } & \multicolumn{1}{c}{ Identificação } \\
\hline AN & Argila natural \\
AP & Argila purificada \\
ANO & Argila natural organofilizada \\
APO & Argila purificada e organofilizada \\
PEBDL & Filme PEBDL puro \\
PEBDL/AN1\% & Filme PEBDL/1\% argila natural \\
PEBDL/AP1\% & Filme PEBDL/1\% argila purificada \\
PEBDL/ANO1\% & Filme PEBDL/1\% argila natural organofilizada \\
PEBDL/APO1\% & Filme PEBDL/1\% argila purificada organofilizada \\
PEBDL/AN 2\% & Filme PEBDL/2\% argila natural \\
PEBDL/AP2\% & Filme PEBDL/2\% argila purificada \\
PEBDL/ANO2\% & Filme PEBDL/2\% argila natural organofilizada \\
PEBDL/APO2\% & Filme PEBDL/2\% argila purificada organofilizada \\
\hline
\end{tabular}


modificadas e não-modificadas organicamente, assim como a natureza alargada dos picos, sugerem uma morfologia intercalada ${ }^{[19]}$. Reduções no espaçamento interplanar basal de argilas organofílicas incorporadas a matrizes poliméricas foram observados em outros sistemas, e atribuídos, ou à degradação do sal orgânico durante o processamento, ou à exsudação e rearranjo do sal orgânico na galeria da $\operatorname{argila}^{[20,21]}$.

\section{Permeabilidade dos filmes ao vapor de água}

A Figura 4 mostra um exemplo dos dados de perda de massa por unidade de área versus tempo, no caso para filmes com $1 \%$ de bentonita purificada e organofilizada.

A Tabela 2 e a Figura 5 apresentam os resultados de permeabilidade ao vapor de água dos filmes de PEBDL e dos compósitos PEBDL/ bentonita obtidos com $1 \%$ e $2 \%$ de argila natural, purificada, natural

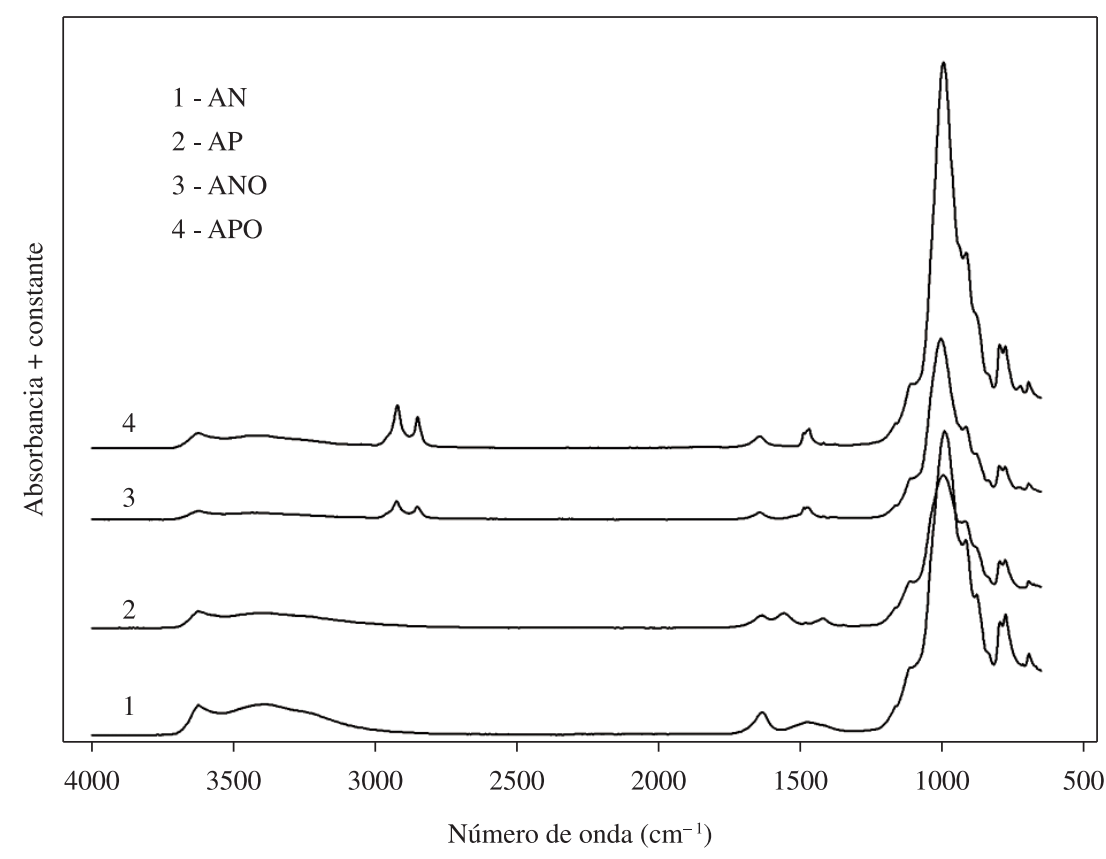

Figura 1. Espectros no infravermelho das argilas (deslocados verticalmente para melhor visualização).

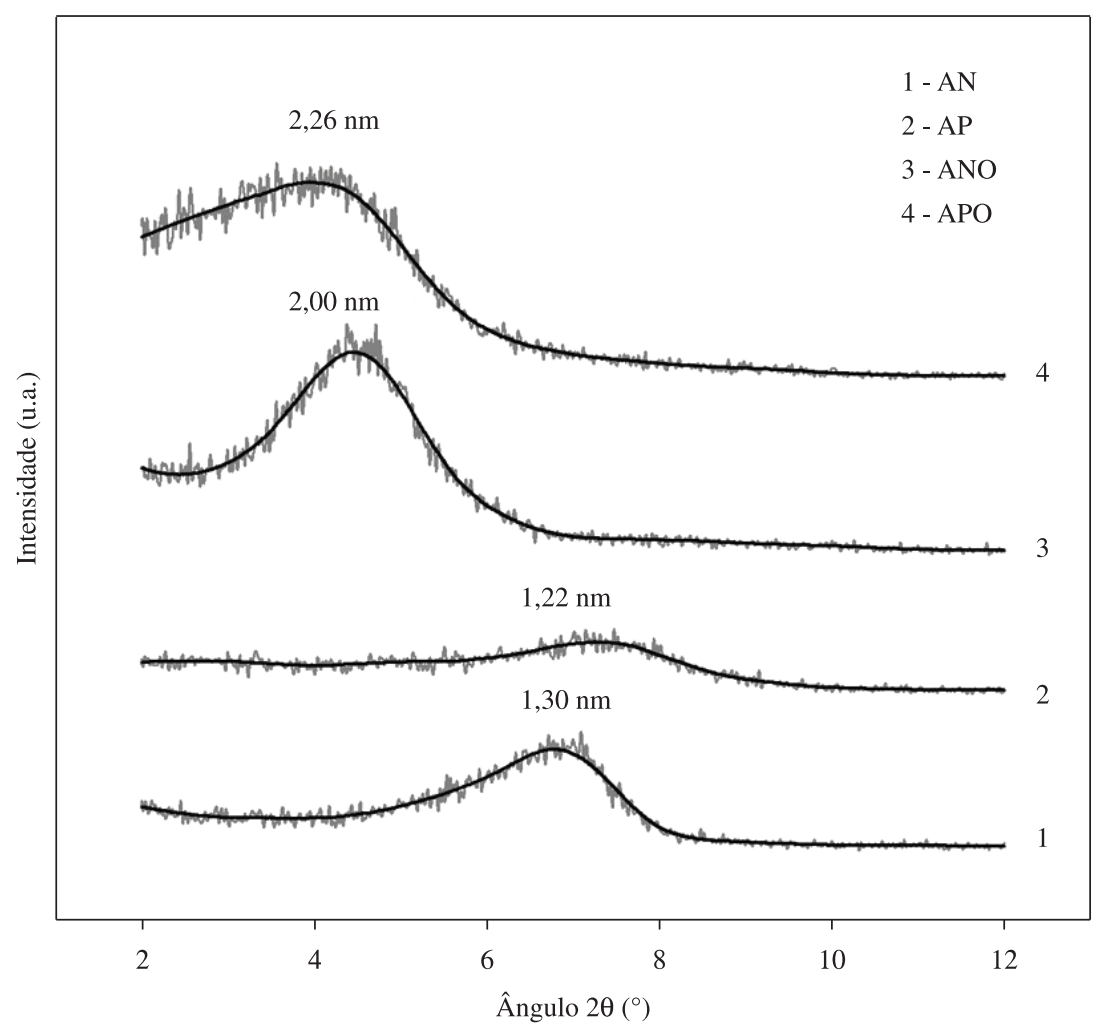

Figura 2. Difractogramas de Raios x das argilas (deslocados verticalmente para melhor visualização). 


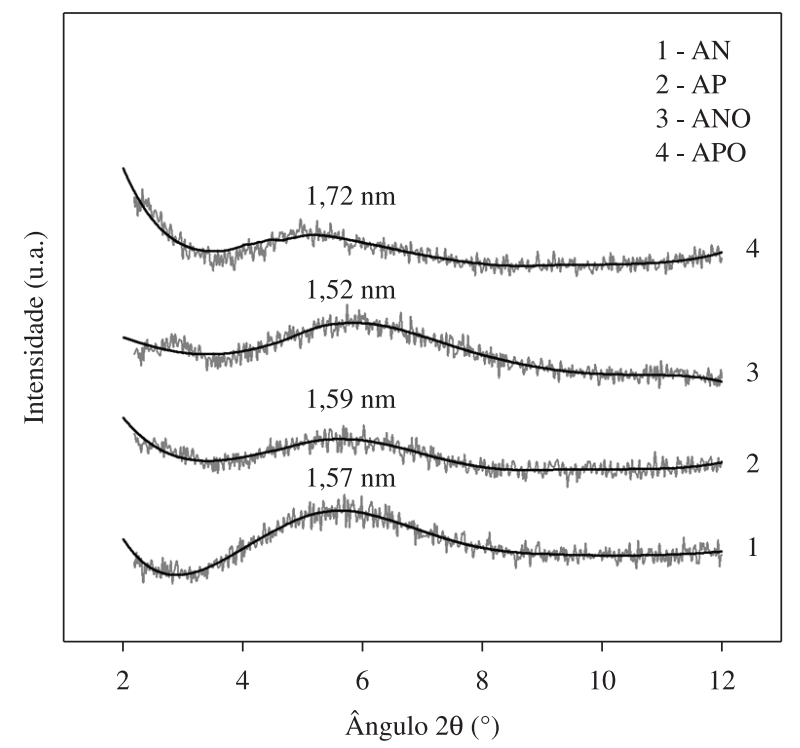

(a)

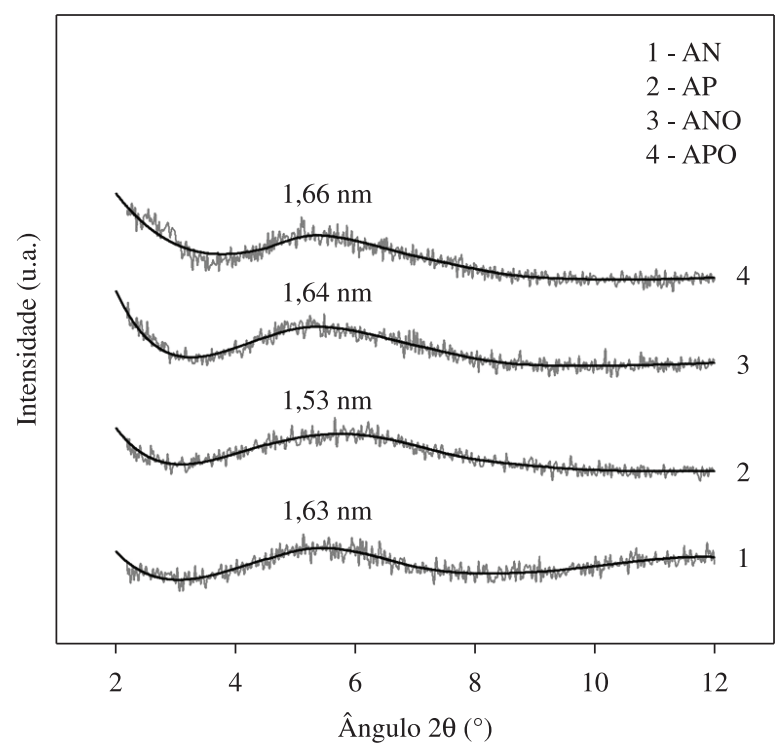

(b)

Figura 3. Difratogramas (DRX) para os filmes PEBDL/bentonita, com 1\% de argila (a) e $2 \%$ de argila (b), deslocados verticalmente para melhor visualização.

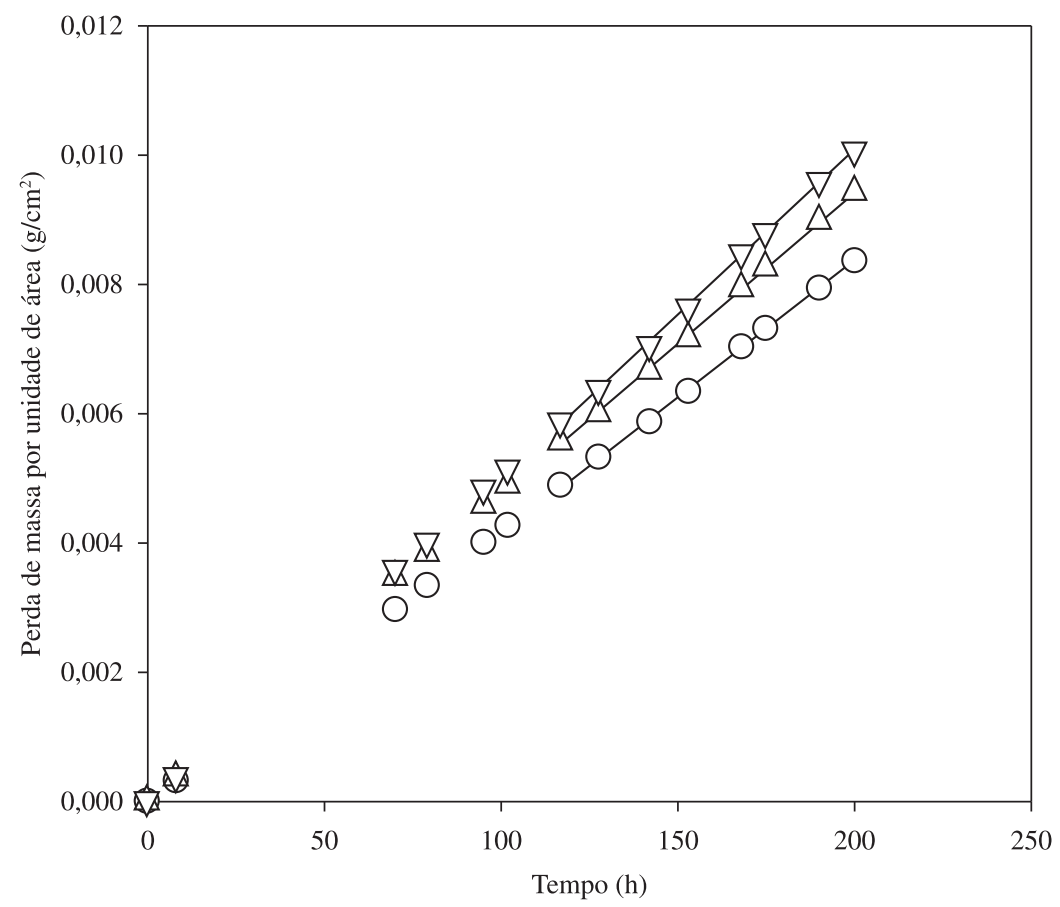

Figura 4. Perda de massa dos potes por unidade de área de filme como função do tempo para três amostras diferentes (triplicatas) do compósito de PEBDL com $1 \%$ de argila bentonita purificada e organofilizada (PEBDL/APO1\%). As linhas correspondem ao intervalo de tempo utilizado para avaliar a permeabilidade.

Tabela 2. Espessura $(h)$, fluxo mássico $(G)$ e permeabilidade $(P)$ dos filmes de PEBDL e nanocompósitos PEBDL/bentonita.

\begin{tabular}{|c|c|c|c|}
\hline Material & $h \times 10^{3}$ & $G \times 10^{6}$ & $P \times 10^{3}$ \\
\hline & $(\mathrm{cm})$ & $\left(\mathrm{g} \cdot \mathrm{cm}^{-2} \cdot \mathrm{h}^{-1}\right)$ & (cm³ $\left.{ }^{3} \mathrm{STP} / \mathrm{cm} . h . b a r\right)$ \\
\hline PEBDL & 2,00 & $45,53 \pm 7,84$ & $3,74 \pm 0,64$ \\
\hline PEBDL/1\% AN & 4,27 & $53,00 \pm 5,12$ & $9,30 \pm 0,90$ \\
\hline PEBDL/1\% AP & 2,92 & $50,57 \pm 4,02$ & $6,07 \pm 0,48$ \\
\hline PEBDL/1\% ANO & 2,82 & $57,83 \pm 17,57$ & $6,70 \pm 2,04$ \\
\hline PEBDL/1\% APO & 3,32 & $44,13 \pm 4,69$ & $6,02 \pm 0,64$ \\
\hline PEBDL $/ 2 \%$ AN & 3,80 & $46,97 \pm 4,60$ & $7,33 \pm 0,72$ \\
\hline PEBDL/2\% AP & 4,70 & $59,73 \pm 11,84$ & $11,53 \pm 2,29$ \\
\hline PEBDL $/ 2 \%$ ANO & 4,54 & $50,97 \pm 0,15$ & $9,50 \pm 0,03$ \\
\hline PEBDL/2\% APO & 5,17 & $40,87 \pm 7,19$ & $8,68 \pm 1,53$ \\
\hline
\end{tabular}




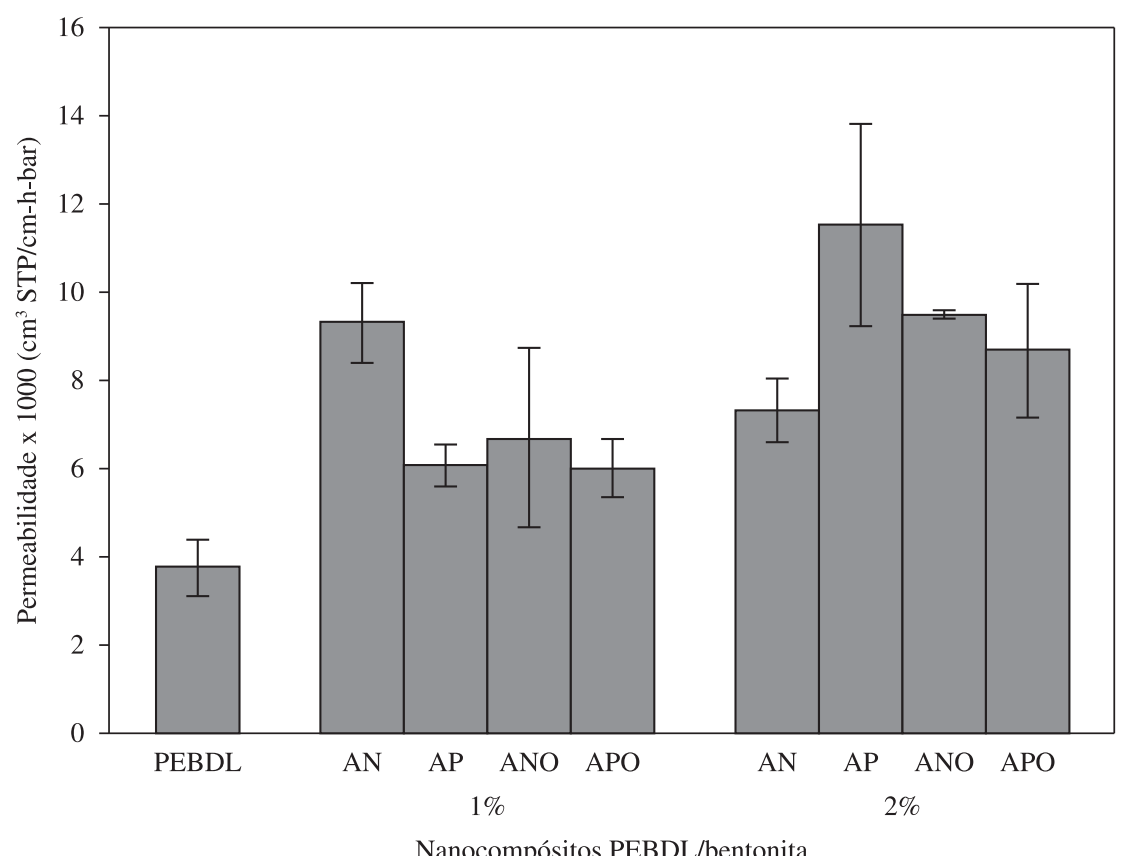

Figura 5. Permeabilidade ao vapor de água dos filmes de PEBDL e dos compósitos PEBDL/bentonita obtidos com $1 \%$ e $2 \%$ de argila natural, purificada, natural organofilizada e purificada organofilizada.

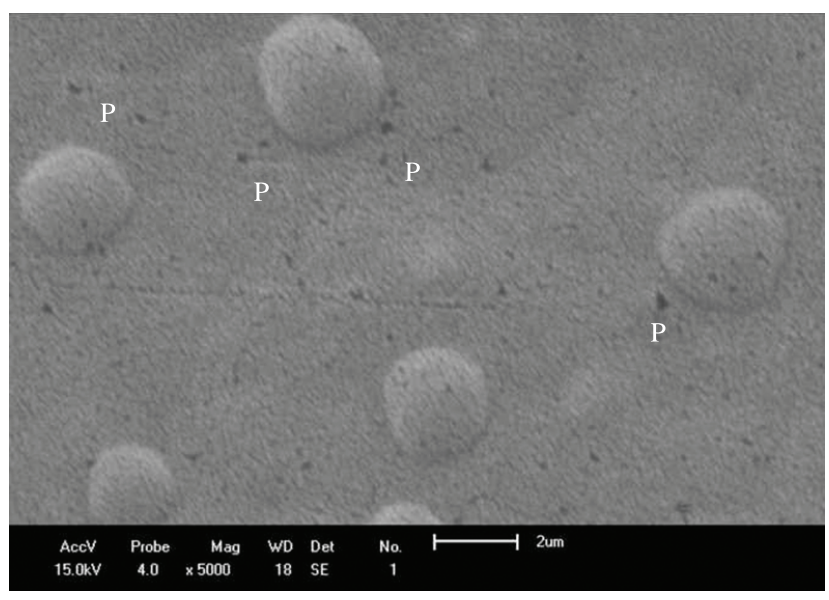

(a)

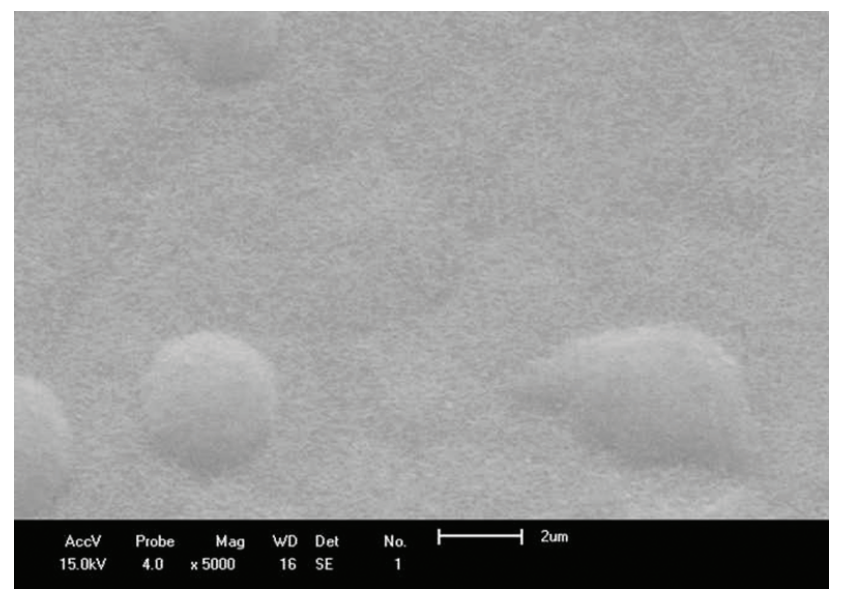

(b)

Figura 6. Imagens MEV (50000×): a) PEBDL/AN 2\% evidenciando a formação de imperfeições superficiais ou poros (P) de 0,2 a 0,4 mm de diâmetro; b) PEBDL puro mostrando a ausência dessas estruturas.

organofilizada e purificada organofilizada. Os testes foram conduzidos em triplicata com filmes de espessura entre 20 e $47 \mathrm{~mm}$; temperaturas entre 26 e $27^{\circ} \mathrm{C}$ e umidade relativa ambiente de $15 \%$. O fluxo mássico de vapor de água em estado estacionário foi avaliado para tempos entre 115 e 200 horas depois do início do teste.

Os resultados obtidos mostram que a adição de argila provocou um aumento considerável da permeabilidade ao vapor de água (80 a 95\%) em relação aos filmes de PEBDL puro. Este resultado pode ser atribuído à maior afinidade da água com a carga argilosa (hidrofílica), comparada com a pouca afinidade entre a água e a matriz apolar (hidrofóbica). Outra possibilidade para o aumento na permeabilidade ao vapor de água pode estar associada à formação de pequenos poros ou falhas no filme polimérico, conforme ilustrado na Figura 6. As imagens de protuberâncias nas micrografias foram analisadas por EDS. Confirmou-se serem pontos de gel da matriz polimérica.

A purificação e/ou organofilização da nanocarga teve um efeito discreto na permeabilidade. Levando em consideração a incerteza das determinações, não foi possível identificar uma tendência estatisticamente significativa nos dados. O nível carga, dentro do limitado intervalo pesquisado ( $1 \%$ e $2 \%$ em massa), também parece ter um efeito reduzido: a permeabilidade média dos filmes com $2 \%$ de nanocarga é $25 \%$ maior que permeabilidade média dos filmes com $1 \%$ de nanocarga.

Existem poucos valores na literatura da permeabilidade ao vapor de água do PEBDL para comparar com o valor obtido neste trabalho, $P=3,8 \cdot 10^{-3} \mathrm{~cm}^{3} \mathrm{STP} / \mathrm{cm}$.h.bar a $26,5^{\circ} \mathrm{C}$. Kamal et al. ${ }^{[22]}$ obtiveram $P=14,8 \cdot 10^{-3} \mathrm{~cm}^{3} \mathrm{STP} / \mathrm{cm}$.h.bar a $38^{\circ} \mathrm{C}$. A última edição do Polymer Handbook ${ }^{[23]}$, na sua compilação bastante completa de permeabilidades, não inclui nenhum valor para o PEBDL. Para 
PEBD e PEAD são citados valores de $2,5 \cdot 10^{-3} \mathrm{~cm}^{3} \mathrm{STP} / \mathrm{cm} . \mathrm{h}$. bar e $0,32 \cdot 10^{-3} \mathrm{~cm}^{3} \mathrm{STP} / \mathrm{cm} . h . b a r$, ambos a $25 \mathrm{C}$, respectivamente. $\mathrm{O}$ valor obtido neste trabalho é comparável a esses valores.

\section{Conclusões}

A purificação da argila bentonita (remoção da matéria orgânica) foi eficiente e resultou em mudanças estruturais que podem ser significativas. A incorporação da argila na matriz de PEBDL resultou na formação de nanocompósitos intercalados em todos os casos. A incorporação da carga argilosa aumentou significativamente a permeabilidade dos filmes ao vapor de água; a purificação e/ou organofilização da argila, assim como o nível de carga, tiveram um efeito moderado na permeabilidade.

\section{Agradecimentos}

Os autores agradecem à Braskem e Bentonit União Nordeste o apoio através da doação dos insumos; ao CNPq e Capes a concessão de bolsas a Carvalho (PQ) e Silva (M) e particularmente, o apoio financeiro concedido pelo CNPq (\# 477808) e FAPESQ (Pronex 202/09).

\section{Referências Bibliográficas}

1. Majumdar, S. K. - "Composites Manufacturing: Materials, Product and Process Engineering", John Wiley, New York (2002).

2. Coelho, A. C. V.; Santos, P. S. \& Santos, H. S. - Quím. Nova, 30, p.1282 (2007). http://dx.doi.org/10.1590/S0100-40422007000500042

3. Leite, I. F.; Carvalho, L. H.; Raposo, C. M. O.; Malta, O. M. L. \& Silva, S. M. L. - J. Therm. Anal. Calorim, 100, p.563 (2010). http://dx.doi org/10.1007/s10973-009-0265-3

4. Esteves, A. C. C.; Timmons, A. B. \& Trindade, T. - Quím. Nova, 27, p.795 (2004).

5. Kim, J.; Lee, J. S. \& Lee J. W. - "Structure and non-linear dynamics of polypropylene layered organoclay nanocomposite", in: Anais do $13^{\circ}$ Congresso Internacional de Reologia, p.33, Cambridge-UK (2000).

6. Kaempfer, D.; Thomann, R. \& Mulhaupt, R. - Polymer, 43, p.2909 (2002). http://dx.doi.org/10.1016/S0032-3861(02)00113-1

7. Ajayan, M.; Schadler, L. S. \& Braun, P. V. - "Nanocomposites Science and Technology", Wiley/VCH, (2003). http://dx.doi.org/10.1002/3527602127

8. Kim, Y. \& White, J. L. - J. Appl. Polym. Sci., 101, p.1657 (2006). http://dx.doi.org/10.1002/app.22196
9. Coutinho, F. M. B.; Mello, I. L. \& Maria, L. C. S. - Polímeros, 13, p.6 (2003).

10. Morales, A. R.; Cruz, C. V. M.; Pereira, O. D. \& Peres L. - Polímeros, 20, p.40 (2010). http://dx.doi.org/10.1590/S0104-14282010005000004

11. Covarrubias, C.; Quijada, R. - J. Memb. Sci., 358, p.33 (2010). http:// dx.doi.org/10.1016/j.memsci.2010.04.026

12. Araújo, S. S.; Araújo, P. E. R.; Raposo, C. M.; Carvalho, L. H. \& Silva, S. M. L. - "Influência da purificação e da organofilização da argila nas propriedades de nanocompósitos PP/Bentonita", in: Anais do $17^{\circ}$ Congresso Brasileiro de Engenharia e Ciência dos Materiais, p.8713, Foz do Iguaçu - PR, nov (2006).

13. Camargo, O. A.; Moniz, A. C. \& Jorge, J. M. A. S. - Bol. tec. Inst. Agron. Campinas, 106, p.94, (1986).

14. Chen, T. J.; Santos, P. S.; Ferreira, H. C.; Calil, S. F.; Zandonadi, A. R. \& Campos, L. V. - Cerâmica, 79, p.305-326 (1974).

15. Paiva, L. B.; Morales, A. R. \& Diaz, F. R. V. - J. Appl. Polym. Sci., 42, p.8 (2008).

16. Madejová, J. - Vib. Spectrosc., 31, p.1 (2003). http://dx.doi. org/10.1016/S0924-2031(02)00065-6

17. Barbosa, R.; Maia, L. F.; Pereira, O. D.; Araújo, E. M.; Melo, T. J. A. \& Ito, E. N. - Polímeros, 16, p.246 (2006).

18. Barbosa, R.; Maia, L. F.; Pereira, O. D.; Araújo, E. M.; Melo, T. J. A. \& Ito, E. N. - Mat. Letters, 61, p.2575 (2007). http://dx.doi.org/10.1016/j. matlet.2006.09.055

19. Utracki, L. A. - "Clay-Containing Polymeric Nanocomposites", Rapra Technology, Sew (2004).

20. Silva, S. M. L. ; López-Manchado, M. A. \& Arroyo, M. - J. Nanosci. Nanotechnol., 7, p.445 (2007).

21. Riva, A.; Zanetti, M.; Braglia, M.; Camino, G. \& Falqui, L. - Polym. Degrad. Stab., 77, p.299 (2002). http://dx.doi.org/10.1016/S01413910(02)00065-4

22. Kamal, M. R.; Jinnah, I. A. \& Utracki, L. A. - Polym. Eng. Sci., 27, p.1337 (1984). http://dx.doi.org/10.1002/pen.760241711

23. Brandrup, J.; Immergut, E. H. \& Grulke, E. A. - "Polymer Handbook", 4. ed., Wiley-International, New York (1999).

Enviado: 06/10/11

Reenviado: $12 / 03 / 12$ Aceito: $14 / 03 / 12$ 